\title{
Cloned Prokaryotic Iron Superoxide Dismutase Protects Yeast Cells against Oxidative Stress Depending on Mitochondrial Location
}

\author{
Rena Balzan, ${ }^{1}$ Dolores R. Agius, and William H. Bannister \\ Department of Physiology and Biochemistry, University of Malta, Msida MSD 06, Malta
}

Received January 25, 1999

Superoxide dismutase (SOD) is considered to be the first line of defense against oxygen toxicity. It exists as a family of three metalloproteins with copper,zinc (Cu,ZnSOD), manganese (MnSOD), and iron (FeSOD) forms. In this work, we have targeted Escherichia coli FeSOD to the mitochondrial intermembrane space (IMS) of yeast cells deficient in mitochondrial MnSOD. Our results show that FeSOD in the IMS increases the growth rate of the cells growing in minimal medium in air but does not protect the MnSOD-deficient yeast cells when exposed to induced oxidative stress. Cloned FeSOD must be targeted to the mitochondrial matrix to protect the cells from both physiological and induced oxidative stress. This confirms that the superoxide radical is mainly generated on the matrix side of the inner mitochondrial membrane of yeast cells, without excluding its potential appearance in the mitochondrial IMS where its elimination by SOD is beneficial to the cells. @1999 Academic Press

Key Words: oxidative stress; Saccharomyces cerevisiae; superoxide dismutase; mitochondrial targeting.

The generation of reactive oxygen species such as the superoxide radical $\left(\mathrm{O}_{2}^{--}\right)$normally associated with cellular respiratory activities (1) and living cells have evolved several mechanisms against these reactive oxygen species. On the first line of defense there are the superoxide dismutase enzymes $\left(\mathrm{SOD}^{2}\right.$; EC 1.15.1.1) (2). In eukaryotic cells, with the exception of a large group of marine arthropods (3), manganese superoxide dismutase (MnSOD) is found exclusively in the mitochondrial matrix (4), and a yeast mutant lacking mitochondrial MnSOD was found to be hypersensitive to oxygen (5). In addition to cytosolic copper, zinc superoxide dismutase ( $\mathrm{Cu}, \mathrm{ZnSOD}$ ), a cyanide-sensitive SOD has been claimed to reside in the mitochondrial intermembrane

${ }^{1}$ To whom correspondence should be addressed. Fax: +356310577. E-mail: rbal1@um.edu.mt.

${ }^{2}$ Abbreviation used: SOD, superoxide dismutase. space of eukaryotic cells $(6-8)$. However, according to Geller and Winge (9), the rat liver $\mathrm{Cu}, \mathrm{ZnSOD}$, previously reported to be localized in the mitochondrial intermembrane space $(7,8)$, was due to lysosomal contamination, even though these authors did not exclude the possibility that a small amount of $\mathrm{Cu}, \mathrm{ZnSOD}$ may be located in the mitochondria.

In this work we tried to acquire a better understanding of the generation and location of the superoxide radical in yeast cells, through differential mitochondrial targeting of the prokaryotic iron superoxide dismutase (FeSOD). We show that Escherichia coli FeSOD, on being imported into the mitochondrial intermembrane space (IMS) of yeast cells deficient in MnSOD, increases the growth rate of the cells growing in minimal medium in the presence of $2 \%$ lactate, though not as efficiently as when the FeSOD is targeted to the mitochondrial matrix. When the MnSODdeficient yeast cells were subjected to induced oxidative stress, or to higher oxygen utilization, cloned FeSOD located in its active form in the mitochondrial IMS, was not able to replace the matrix MnSOD in its activity against oxidative stress.

\section{MATERIALS AND METHODS}

Bacterial and yeast strains. The $E$. coli strain used in the standard cloning procedures was TG1 (supE hsd $\Delta 5$ thi $\Delta$ (lac-proAB) $F^{\prime}\left[\operatorname{traD} 36\right.$ pro $A B^{+}$lacI $T^{q}$ lacZ $\left.\Delta M 15\right]$ ) obtained from Amersham International. The Saccharomyces cerevisiae strains used were (i) $\mathrm{DL}_{1 \mathrm{Mn}^{-}}(\alpha$, leu2-3, -112 his3-11, -15 ura3-251, $-372,-328$ sod2::LEU2) (5), kindly provided by S. Oliver of Manchester University, and (ii) $\mathrm{DL} 1 \mathrm{Mn}^{-} \mathrm{Fe}^{+}-\mathrm{P}$, which is $\mathrm{DL} 1 \mathrm{Mn}^{-}$carrying the $E$. coli FeSOD gene with the yeast MnSOD gene targeting signal on the recombinant plasmid YEp/PGK-S (10).

Construction of plasmid vector for expressing $E$. coli FeSOD with the yeast cytochrome $c_{1}$ targeting signal in $S$. cerevisiae. The E. coli FeSOD gene (11) was isolated from the plasmid pHS1-8 (donated by D. Touati, Institut Jacques Monod, Paris) by digestion with the restriction endonucleases AsuII and ClaI and then ligated to the plasmid pDVL45 (12) (donated by G. Schatz, Basel University, Switzerland) at its Bam HI site (downstream to the yeast cytochrome $c_{1}$ leader sequence $\left(\mathrm{pC}_{1}\right)$ ) to form the recombinant plasmid $\mathrm{pDVL} 45-\mathrm{F}$. 
The $E$. coli FeSOD gene with the yeast cytochrome $c_{1}$ leader sequence was isolated from the plasmid pDVL45-F by digestion with the restriction endonucleases SpeI and StuI, and then ligated to the plasmid YEp/PGK (supplied by S. Oliver, Manchester University) at its $B g l I I$ site (flanked by the yeast 3-phosphoglycerate kinase gene $(P G K)$ promoter and transcription terminator) to form the recombinant plasmid $\mathrm{YEp} / \mathrm{PGK}-\mathrm{C}_{1} \mathrm{~F}$. All ligation experiments using $E$. coli TG1 cells as the transformation host were carried out as specified by Sambrook et al. (13).

Expression of E. coli FeSOD with the yeast cytochrome $c_{1}$ targeting signal in yeast cells. Transformation of $S$. cerevisiae $\mathrm{DL} 1 \mathrm{Mn}^{-}$cells (carrying an inactivated MnSOD gene) (5) by the recombinant plasmid $\mathrm{YEp} / \mathrm{PGK}-\mathrm{C}_{1} \mathrm{~F}$ (to give rise to the strain $\mathrm{DL} 1 \mathrm{Mn}^{-}-\mathrm{YEp}-\mathrm{C}_{1} \mathrm{~F}$ ) and $\mathrm{YEp} / \mathrm{PGK}$ (to give rise to the strain $\mathrm{DL} 1 \mathrm{Mn}^{-}-\mathrm{YEp}$ ), respectively, was carried out by the lithium acetate method according to Ito et al. (14). The culture media used were (i) YEPD (ii) minimal medium (Bacto Yeast Nitrogen Base without amino acids, 0.67\%; glucose, 1\%; L-lactate, $2 \%$; with adenine sulfate, L-methionine and uracil (each at $20 \mu \mathrm{g} / \mathrm{ml})$, L-histidine-HCl $(100 \mu \mathrm{g} / \mathrm{ml})$, L-tryptophan $(40 \mu \mathrm{g} / \mathrm{ml})$, L-lysine-HCl $(30 \mu \mathrm{g} / \mathrm{ml})$, and L-leucine $(120 \mu \mathrm{g} / \mathrm{ml})$, as required, and $\mathrm{pH}$ adjusted to 5.5 with $\mathrm{KOH}$ ). For plates $2 \%$ agar was used and incubation was at $28^{\circ} \mathrm{C}$. Aerobic growth in liquid cultures was maintained at $28^{\circ} \mathrm{C}$ with constant shaking at $300 \mathrm{rpm}$.

Isolation and subfractionation of yeast mitochondria. The protocols used for the isolation of the membrane-free cytosolic fraction, mitochondria, intermembrane space fraction, mitochondrial matrix, and mitochondrial membranes were as described by Glick and Pon (15).

Determination of protein expression and activity. Protein expression studies were carried out by using SDS-polyacrylamide gel electrophoresis followed by staining with Coomassie brilliant blue (16). SOD activity was determined according to McCord and Fridovich $(17,18)$, and for SOD activity staining the method of Beauchamp and Fridovich (19) was used. Catalase (CAT; EC 1.11.1.6) activity was determined according to the method of Aebi (20). Cytochrome $c$ peroxidase (CCP; EC 1.11.1.5) enzyme assays were carried out as specified by Yonetani (21).

Response to oxidative stress. In the study of the response of $S$. cerevisiae strains DL1Mn $-\mathrm{YEp}, \mathrm{DL}^{-} \mathrm{Mn}^{-}-\mathrm{YEp}-\mathrm{C}_{1} \mathrm{~F}$, and DL1Mn ${ }^{-}$$\mathrm{Fe}^{+}-\mathrm{P}$ (having cloned $E$. coli FeSOD in the mitochondrial matrix) (10) to induced oxidative stress, the yeast cells were exposed to (i) $1 \mathrm{mM}$ or $6 \mathrm{mM}$ paraquat (Sigma) in minimal medium and YEPD respectively; and (ii) a wide range of menadione (Sigma) concentrations (1 $\mathrm{mM}$ to $6 \mathrm{mM}$ ) in YEPD medium for $1 \mathrm{~h}$, followed by plating of resuspended cells on minimal medium plates to study cell viability. Cellular growth of the three strains exposed to paraquat was followed by measuring the optical density (OD) at $600 \mathrm{~nm}$ in a PerkinElmer Lambda 17 spectrophotometer after appropriate dilution of the cell cultures. The response of the recombinant yeast cells to "physiological" oxidative stress was studied by growing the cells in YPE liquid medium in air.

Miscellaneous. DNA sequencing was carried out by the dideoxy method (22) using Sequenase I enzyme (United States Biochemicals). The Bradford procedure was used to determine protein concentrations (23). Electroblotting of proteins from SDS-polyacrylamide gels on to nitrocellulose membranes (Hybond-C extra, from Amersham) was carried out on a Pharmacia LKB 2117-250 Novablot electrophoresis transfer kit. For subsequent immunoscreening of the proteins the Amersham SuperScreen system was used. Densitometry studies were carried out on Bio-Rad Multi-Analyst/PC Version 1.1.

\section{RESULTS}

Targeting of E. coli FeSOD to the intermembrane space of yeast mitochondria in vivo. The prokaryotic FeSOD gene with the leader sequence of the yeast cytochrome $c_{1}$ gene was expressed in $S$. cerevisiae

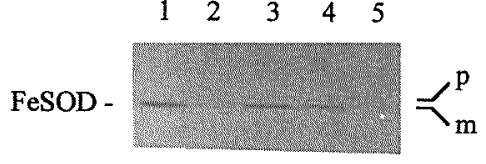

FIG. 1. Immunoscreening for $E$. coli FeSOD in $S$. cerevisiae DL $1 \mathrm{Mn}^{-}-\mathrm{YEp}-\mathrm{C}_{1} \mathrm{~F}$ cells containing $E$. coli FeSOD with the yeast cytochrome $c_{1}$ targeting signal. The electroblotting on to a nitrocellulose membrane, following gel electrophoresis, was done from a $5 \%$ $(\mathrm{w} / \mathrm{v})$ stacking, $12 \%(\mathrm{w} / \mathrm{v})$ resolving SDS-polyacrylamide gel. Lane 1 contains $2 \mu \mathrm{g}$ of $E$. col $i$ FeSOD (Sigma). Lane 2 contains $30 \mu \mathrm{g}$ of total protein from the membrane-free cytosolic fraction. Lanes 3 to 5 contain $9 \mu \mathrm{g}$ each of total protein from the IMS fraction, matrix, and mitochondrial membranes, respectively. p, precursor form of FeSOD fusion protein; $m$, mature FeSOD after cleavage of the cytochrome $c_{1}$ targeting signal.

$\mathrm{DL} 1 \mathrm{Mn}^{-}-\mathrm{YEp}-\mathrm{C}_{1} \mathrm{~F}$ cells. Protein expression studies, together with electroblotting and subsequent immunoscreening by means of $E$. coli FeSOD antibody, revealed the presence of FeSOD in the isolated mitochondrial intermembrane space (IMS) fraction of S. cerevisiae cells (Fig. 1, lane 3). From a series of immunoscreening experiments with antibodies for yeast hexokinase, hsp60, cytochrome $c$ oxidase subunit IV, and $29 \mathrm{kDa}$ porin (all yeast antibodies were kindly provided by G. Schatz of Basel University), the mitochondrial IMS fraction of the $S$. cerevisiae cells (confirmed as IMS fraction by immunoscreening with cytochrome $b_{2}$ antibody) was found not to be contaminated by the cytosol, or the outer mitochondrial membrane, and only very slightly and insignificantly contaminated by the matrix and inner membrane. The mitochondrial matrix fraction was contaminated by the cytochrome $b_{2}$ of the IMS fraction (results not shown). Densitometry showed comparable contamination of matrix by IMS fraction for cytochrome $b_{2}$ and FeSOD. This corresponds with the presence of a fainter FeSOD band in lane 4 of Fig. 1.

The import of the prokaryotic protein into the mitochondria of yeast cells was accompanied by the proteolytic removal of the yeast cytochrome $c_{1}$ presequence as judged by electrophoretic behavior (Figs. 1 and 2), and the enzymatic activity of the mature protein is shown in Fig. 2. The absence of a second activity band in Fig. 2 (lanes 4 and 8 ) indicates that the cyt $c_{1}$-FeSOD precursor is inactive since the precursor protein has a different mobility from that of the mature protein.

The fact that in DL1Mn ${ }^{-} \mathrm{Fe}^{+}-\mathrm{P}$ cells the mitochondrial FeSOD activity level was much higher than in DL1 $\mathrm{Mn}^{-}-\mathrm{YEp}-\mathrm{C}_{1} \mathrm{~F}$ cells (Table 1), indicates that the mitochondrial matrix can support a much higher FeSOD activity level than the IMS. One cannot exclude the possibility that the MnSOD targeting signal used in DL1Mn ${ }^{-} \mathrm{Fe}^{+}-\mathrm{P}$ cells is more efficient than the cytochrome $c_{1}$ targeting signal used in DL1Mn ${ }^{-}-\mathrm{YEp}-\mathrm{C}_{1} \mathrm{~F}$. In DL1 $\mathrm{Mn}^{-} \mathrm{Fe}^{+}-\mathrm{P}$ cells the MnSOD presequence is not cleaved off (10) and the precursor protein is active both 


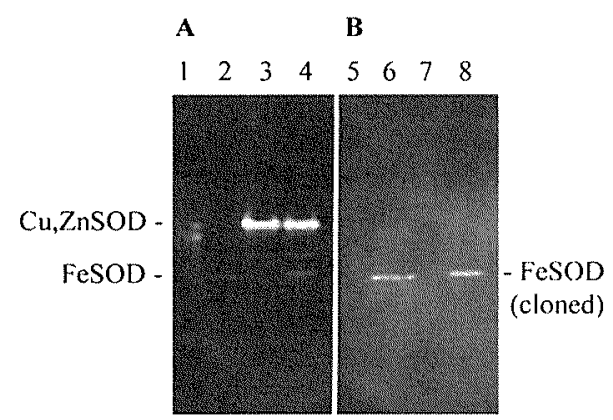

FIG. 2. Activity stain of $E$. coli FeSOD targeted to the mitochon-

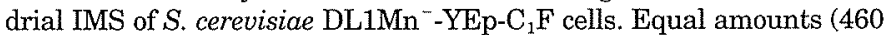
$\mu \mathrm{g}$ ) of total protein from DL1Mn--YEp cells (lanes 3 and 7) and DL1Mn ${ }^{-}-\mathrm{YEp}-\mathrm{C}_{1} \mathrm{~F}$ cells (lanes 4 and 8) were loaded in their respective lanes on $10 \%(\mathrm{w} / \mathrm{v})$ polyacrylamide native gels $\mathrm{A}$ and $\mathrm{B}$. Lanes 1 and 5 contain $2 \mu \mathrm{g}$ each of human Cu,ZnSOD (Sigma), and lanes 2 and 6 contain $5 \mu \mathrm{g}$ each of $E$. coli FeSOD (Sigma). Gel B was treated with 10 $\mathrm{mM} \mathrm{KCN}$ prior to the activity staining to inactivate $\mathrm{Cu} / \mathrm{ZnSOD}$.

in the mitochondrial matrix and in the cytosol (Table 1). However, it has already been proved that active FeSOD located in the cytosol cannot replace mitochondrial MnSOD in protecting yeast cells against oxidative stress (10). In this work, since FeSOD activity was determined in cells harvested at mid-logarithmic phase, the result obtained from $\mathrm{DL} 1 \mathrm{Mn}^{-} \mathrm{Fe}^{+}-\mathrm{P}$ cells was higher than in previous work (10) where the activity was measured in cells harvested at stationary phase. This has been observed with other yeast strains in our laboratory (24). The threefold increase in CAT activity in DL1Mn ${ }^{-} \mathrm{Fe}^{+}-\mathrm{P}$ cells (Table 1 ) is probably due to the much higher SOD activity level in the cell, and it indicates that it is CAT and not CCP which controls the $\mathrm{H}_{2} \mathrm{O}_{2}$ level within the yeast cells. The observed tendency to increase in CCP activity registered in $\mathrm{DL} 1 \mathrm{Mn}^{-}-\mathrm{YEp}-\mathrm{C}_{1} \mathrm{~F}$ cells (Table 1) points towards the possibility of having a more efficient means of removing $\mathrm{H}_{2} \mathrm{O}_{2}$ from the mitochondrial IMS as soon as it is formed.

Role of cloned $\mathrm{FeSOD}$ in protecting yeast cells against oxidative stress depends on mitochondrial location. When growing in minimal medium in the absence of paraquat, DL1Mn ${ }^{-}-\mathrm{YEp}_{\mathrm{C}} \mathrm{C}_{1} \mathrm{~F}$ cells with FeSOD targeted

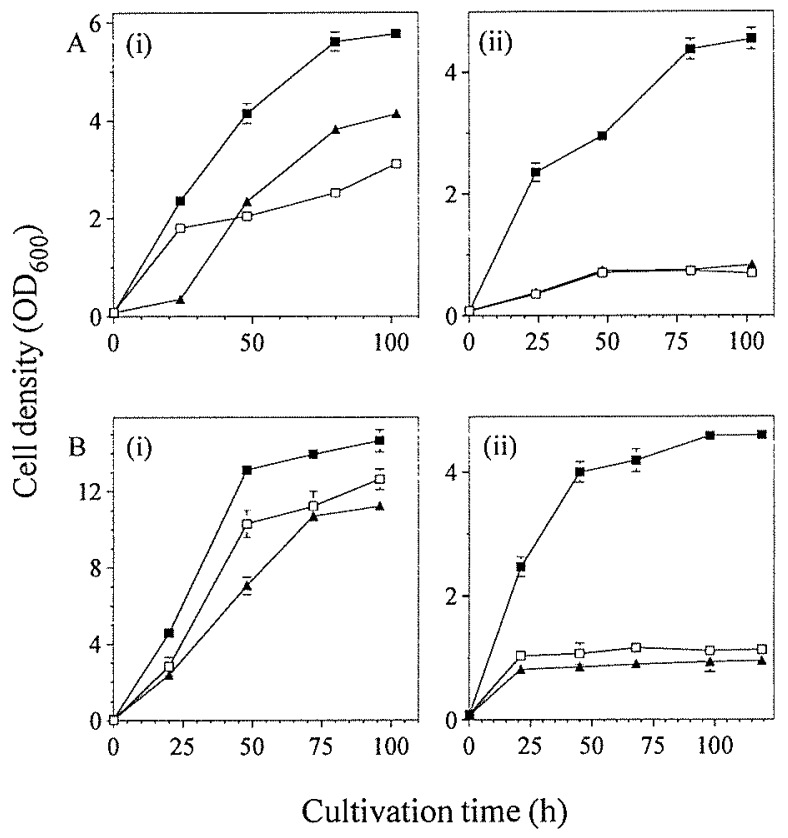

FIG. 3. Exponential growth curves of $S$. cerevisiae strains DLIMn ${ }^{-}-\mathrm{YEp}-\mathrm{C}_{2} \mathrm{~F}, \mathrm{DL} 1 \mathrm{Mn}^{-} \mathrm{Fe}^{+}-\mathrm{P}$ and DL1Mn--YEp. Cells from the $S$. cerevisiae strains DL1 $\mathrm{Mn}^{-}-\mathrm{YEp}-\mathrm{C}_{1} \mathrm{~F}$ (MnSOD-deficient mutant with $E$. coli FeSOD targeted to the IMS, s), DL1Mn ${ }^{-} \mathrm{Fe}^{+}-\mathrm{P}$ (MnSOD-deficient mutant with $E$. coli FeSOD targeted to the mitochondrial matrix, $\mathbf{D}$ ), and DL1Mn"-YEp (MnSOD-deficient mutant which carries only the plasmid YEp/PGK, $\square$ ) were grown in liquid minimal medium (A) containing $0 \mathrm{mM}$ paraquat (i), or $1 \mathrm{mM}$ paraquat (ii), and in YEPD medium (B) containing $0 \mathrm{mM}$ paraquat (i), or $6 \mathrm{mM}$ paraquat (ii). Each point represents the mean of three independent determinations. Error bars are $\pm 1 \mathrm{SD}$ and appear where sufficiently large.

to the IMS had a better growth rate than DL1Mn ${ }^{-}$-YEp cells which carry only the plasmid YEp/PGK without the cloned $\mathrm{FeSOD}$ gene. However, the growth rate of DL $1 \mathrm{Mn}^{-}-\mathrm{YEp}-\mathrm{C}_{1} \mathrm{~F}$ cells was less than that of DL1Mn ${ }^{-} \mathrm{Fe}^{+}-\mathrm{P}$ cells with FeSOD targeted to the mitochondrial matrix (10) (Fig. 3A(i)). In rich YEPD medium, the differences in growth rates of the three recombinant strains were not so marked since, during fermentation, respiration is mainly anaerobic (Fig. 3B(i)).

In YPE medium with ethanol as the non-fermentable carbon source, as well as in minimal or YEPD medium

TABLE 1

Antioxidant Enzyme Activities

\begin{tabular}{|c|c|c|c|c|c|}
\hline Yeast strains & $\mathrm{Cu}, \mathrm{ZnSOD}$ & $\begin{array}{c}\text { FeSOD } \\
\text { (mitochondrial) }\end{array}$ & $\begin{array}{l}\text { FeSOD } \\
\text { (cytosolic) }\end{array}$ & CAT & CCP \\
\hline DL1Mn ${ }^{-}-Y E p$ & $25.1 \pm 0.98$ & - & - & $18.2 \pm 2.5$ & $1.06 \pm 0.04$ \\
\hline DL1Mn ${ }^{-}-Y E p-C_{1} F$ & $17.4 \pm 1.21$ & $5.9 \pm 0.72$ & - & $17.9 \pm 1.3$ & $1.50 \pm 0.14$ \\
\hline $\mathrm{DL}_{1 \mathrm{Mn}} \mathrm{Fe}^{+}-\mathrm{P}$ & $22.7 \pm 1.96$ & $62.8 \pm 2.45$ & $19.91 \pm 1.69$ & $55.8 \pm 3.4$ & $1.16 \pm 0.18$ \\
\hline
\end{tabular}

Note. Cells were grown in minimal medium and harvested at midlogarithmic phase. Specific activity was determined in triplicate on at least three independent extracts. Cytochrome $c$ peroxidase (CCP) activity was normalized to $20 \mu \mathrm{M}$ cytochrome $c$ concentration in the assay. Data are given with the SE of the estimate. Specific activities of copper,zinc superoxide dismutase (Cu,ZnSOD), mitochondrial and cytosolic iron superoxide dismutase (FeSOD), catalase (CAT), and CCP are quoted as U/mg of total cell protein. 


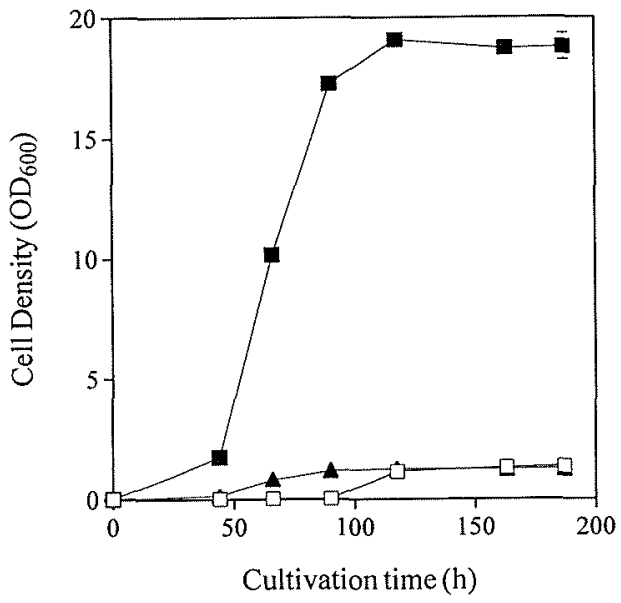

FIG. 4. S. cerevisiae DL1Mn ${ }^{-} \mathrm{Fe}^{+}-\mathrm{P}$ cells with $E$. coli FeSOD in the mitochondrial matrix have a significant growth advantage over

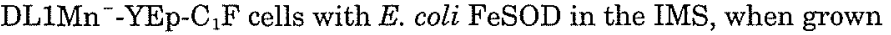
on a nonfermentable carbon source. Cells from the $S$. cerevisiae strains $\mathrm{DL} 1 \mathrm{Mn}{ }^{-}-\mathrm{YEp}-\mathrm{C}_{1} \mathrm{~F}$ (MnSOD-deficient mutant with $E$. coli FeSOD targeted to the IMS, s), DL1 $\mathrm{Mn}^{-} \mathrm{Fe}^{+}-\mathrm{P}$ (MnSOD-deficient mutant with $E$, coli FeSOD targeted to the mitochondrial matrix, $\mathbf{\square}$ ), and DL1Mn ${ }^{-}$-YEp (MnSOD-deficient mutant which carries only the plasmid YEp/PGK, $\mu$ ) were grown in YPE medium at $28^{\circ} \mathrm{C}$. Each point represents the mean of three independent determinations. Error bars are \pm 1 SD and appear where sufficiently large.

in the presence of paraquat or manadione, the survival rate of DL1Mn ${ }^{-}-\mathrm{YEp}-\mathrm{C}_{1} \mathrm{~F}$ cells with FeSOD in the mitochondrial IMS was not different from that of DL1Mn ${ }^{-}$-YEp cells without any cloned FeSOD (Figs. $3 \mathrm{~A}(\mathrm{ii})$ and $\mathrm{B}(\mathrm{ii}), 4$, and 5). That the failure of the IMStargeted FeSOD to protect the cells from oxidative stress is not simply a consequence of low expression, but one of localization, is proved by the fact that the FeSOD activity of $5.9 \mathrm{U} / \mathrm{mg}$ of total protein (Table 1 ), which is equivalent to $\sim 60 \mathrm{U} / \mathrm{mg}$ of mitochondrial protein, would have been sufficient, if located in the matrix, to protect the cells against oxidative stress. It has also been shown in previous work (5) that a comparable level of mitochondrial SOD activity in the matrix of wild-type yeast cells did protect the cells against oxidative stress. Hence, the presence of SOD in the matrix, as opposed to that in the IMS, is essential for protection against induced oxidative stress.

\section{DISCUSSION}

In this work, $E$. coli FeSOD was targeted to the mitochondrial IMS of $S$. cerevisiae cells deficient in MnSOD. The yeast cytochrome $c_{1}$ targeting signal was cleaved off and the resulting mature FeSOD proved to be active whilst the precursor protein did not show any activity. This is in contrast to a previously constructed fusion protein consisting of FeSOD with the yeast MnSOD presequence which gave rise to an active precursor protein (10). Therefore, the in vivo folding of the mature FeSOD as part of a precursor protein appears to depend on the nature of the presequence.

Our results show that MnSOD-deficient yeast cells having cloned $E$. coli FeSOD targeted to the mitochondrial IMS behave differently than when having the cloned FeSOD targeted to the matrix. The fact that the presence of FeSOD in the IMS increases the growth rate of the cells growing in minimal medium in air, even though not to the extent as when the FeSOD is located in the matrix (Fig. 3A(i)), points towards a possible relevance of the presence of SOD in the mitochondrial IMS of yeast cells. However, the presence of FeSOD in the IMS did not protect the MnSODdeficient yeast cells when exposed to induced oxidative stress (Figs. 3A(ii) and B(ii) and Fig. 5), or when growing on a nonfermentable carbon source such as ethanol (Fig. 4). Under these conditions cloned FeSOD has to be targeted to the mitochondrial matrix to protect the cells from oxidative stress. Similar results were also obtained in our laboratory, when $E$. coli FeSOD was targeted to the IMS of $S$. cerevisiae cells deficient in both MnSOD and $\mathrm{Cu}, \mathrm{ZnSOD}$. The double mutant strain carrying FeSOD in the IMS showed a 53\% increase in growth rate over the double mutant strain carrying the plasmid only, after $95 \mathrm{~h}$ of growth in minimal medium. In the presence of $1 \mathrm{mM}$ paraquat, both double mutant strains with, or without FeSOD in the IMS, could not survive (unpublished results).

The protection given by FeSOD located in the IMS to MnSOD-deficient yeast cells growing in minimal me-

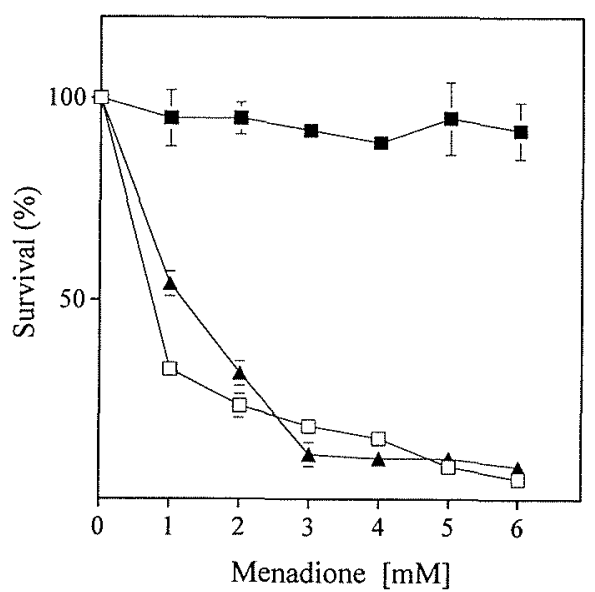

FIG. 5. Sensitivity to menadione of MnSOD-deficient yeast cells with cloned FeSOD targeted either to the mitochondrial matrix or the IMS. Cells from the $S$. cerevisiae strains DL1Mn ${ }^{-}-\mathrm{YEp}_{\mathrm{C}} \mathrm{C}_{1} \mathrm{~F}$ (MnSOD-deficient mutant with $E$. coli FeSOD targeted to the IMS, A), DL1 $\mathrm{Mn}^{-} \mathrm{Fe}^{+}-\mathrm{P}$ (MnSOD-deficient mutant with $E$. coli FeSOD targeted to the mitochondrial matrix, $\mathbf{\square}$ ), and DL1Mn ${ }^{-}-\mathrm{YEp}$ (MnSOD-deficient mutant which carries only the plasmid YEp/PGK, $\square$ ) were exposed to a wide range of menadione concentrations ( 1 to 6 $\mathrm{mM}$ ) in YEPD medium for $1 \mathrm{~h}$, followed by plating of resuspended cells on minimal medium plates to study cell viability. Data are the mean of triplicates from a representative experiment. Error bars are $\pm 1 \mathrm{SD}$ and appear where sufficiently large. 
dium in air and exposed to the normal flux of $\mathrm{O}_{2}^{--}$ indicates the potential appearance of $\mathrm{O}_{2}^{--}$in the mitochondrial IMS of the cells where its elimination by SOD is beneficial to the cells. However, since the greater protection against oxidative stress to the MnSOD-deficient yeast cells occurs when FeSOD is targeted to the matrix, the actual generation of $\mathrm{O}_{2}^{\cdot-}$ seems to occur on the inner side of the inner membrane, thus confirming what has been previously suggested $(23,24)$. This does not preclude the possibility of some generation of the superoxide radical on the outer side of the inner membrane. Other possibilities may include leakage of the superoxide radical from the matrix through the inner membrane (25), especially in strains deficient in MnSOD, and scavenging of superoxide radical coming from the cytosol (26).

In summary, we have shown (i) that in vivo, the mitochondrial IMS of yeast cells can support the function of a targeted SOD with resultant protection to the MnSODdeficient yeast cells growing in minimal medium in air, when exposed to the normal flux of $\mathrm{O}_{2}^{--}$; and (ii) that this IMS-located SOD cannot replace the matrix SOD not only in protecting the cells against induced oxidative stress, but also when the yeast cells are growing on a non-fermentable carbon source, thus confirming the suggestions that the generation of $\mathrm{O}_{2}^{--}$occurs mainly on the inner side of the mitochondrial inner membrane, without precluding the possibility of damaging appearance of some $\mathrm{O}_{2}^{--}$in the mitochondrial IMS.

\section{ACKNOWLEDGMENTS}

We thank Professor D. Touati for providing us with plasmid pHS1-8 and the antibody for E. coli FeSOD and Professor S. Oliver for supplying us with the $S$. cerevisiae $\mathrm{DL} 1 \mathrm{Mn}^{-}$strain and the plasmid vector YEp/PGK. We also thank Professor G. Schatz for supplying us with the plasmid vector pDVL45, antibodies for yeast mitochondrial marker proteins, and hexokinase and especially for his advice and support. This work was supported by a Research Fund Grant from the University of Malta.

\section{REFERENCES}

1. Fridovich, I. (1975) Annu. Rev. Biochem. 44, 147-159.

2. Fridovich, I. (1978) Science 201, 875-880.

3. Brouwer, M., Brouwer, T. H., Grater, W., Enghild, J. J., and Thogersen, I. B. (1997) Biochemistry 36, 13381-13388.
4. Weisiger, R. A., and Fridovich, I. (1973) J. Biol. Chem. 248, 3582-3592.

5. van Loon, A. P. G. M., Pesold-Hurt, B., and Schatz, G. (1986) Proc. Natl. Acad. Sci. USA 83, 3820-3824.

6. Weisiger, R. A., and Fridovich, I. (1973) J. Biol. Chem. 248, 4793-4796.

7. Peeters-Joris, C., Vandevoorde, A. M., and Baudhuin, P. (1975) Biochem. J. 150, 31-39.

8. Tyler, D. D. (1975) Biochem. J. 147, 493-504.

9. Geller, B. L., and Winge, D. R. (1982) J. Biol. Chem. 257, 89458952.

10. Balzan, R., Bannister, W. H., Hunter, G. J., and Bannister, J. V. (1995) Proc. Natl. Acad. Sci. USA 92, 4219-4223.

11. Carlioz, A., Ludwig, M. L., Stallings, W. C., Fee, J. A., Steinman, H. M., and Touati, D. (1988) J. Biol. Chem. 263, 1555-1562.

12. van Loon, A. P. G. M., Brändli, A. W., and Schatz, G. (1986) Cell 44, 801-812.

13. Sambrook, J., Fritsch, E. F., and Maniatis, T. (1989) Molecular Cloning: A Laboratory Manual, 2nd ed., Cold Spring Harbor Laboratory Press, Cold Spring Harbor, NY.

14. Ito, H., Jukuda, Y., Murata, K., and Kimura, A. (1983) J. Bacteriol. 153, 163-168.

15. Glick, B. S., and Pon, L. A. (1995) Methods Enzymol. 260, 213223.

16. Sedmak, J. J., and Grossberg, S. E. (1977) Anal. Biochem. 79, 544-552.

17. McCord, J. M., and Fridovich, I. (1969) J. Biol. Chem. 244, 6049-6055.

18. Ysebaert-Vanneste, M., and Vanneste, W. H. (1980) Anal. Biochem. 107, 86-95.

19. Beauchamp, C., and Fridovich, I. (1971) Anal. Biochem. 44, $276-287$.

20. Aebi, H. E. (1983) in Methods of Enzymatic Analysis (Bergmeyer, H. U., Ed.), Vol. 3, 3rd ed., pp. 273-286, Verlag Chemie, Deerfield Beach, FL.

21. Yonetani, T. (1967) in Methods in Enzymology (Estabrook, R. W., and Pullman, M. E., Eds.), Vol. X, pp. 336-339, Academic Press, NY.

22. Sanger, F., Nicklin, S., and Coulson, A. R. (1977) Proc. Natl. Acad. Sci. USA 74, 5463-5467.

23. Bradford, M. (1976) Anal. Biochem. 72, 248-254.

24. Agius, D. R., Bannister, W. H., and Balzan, R. (1998) Biochem. Mol. Biol. Int. 44, 41-49.

25. Longo, V. D., Butler Gralla, E., and Selverstone Valentine, J. (1996) J. Biol. Chem. 271, 12275-12280.

26. Guidot, D. M., Repine, J. E., Kitlowski, A. D., Flores, S. C., Nelson, S. K., Wright, R. M., and McCord, J. M. (1995) J. Clin. Invest. 96, 1131-1136. 